\title{
EL CINE DE BERLANGA Y SU PROYECCIÓN INTERNACIONAL
}

\author{
Kepa Sojo Gil \\ Universidad del País Vasco (UPV/EHU)
}

\begin{abstract}
RESUMEN: Luis García Berlanga es quizás el director más importante que el cine español ha dado. Sin embargo no es tan conocido internacionalmente como merece. Su espaldarazo internacional comienza en 1953, en el Festival de Cannes, donde obtiene dos premios con su genial filme Bienvenido Mister Marshall (1952). Entre ese año y 1981 el valenciano participa en varias ocasiones en los mejores certámenes cinematográficos del mundo: Cannes, Venecia, Berlín, y uno de sus mejores filmes, Plácido (1961), es nominado a los Oscar de Hollywood. Este artículo pretende recordar la trayectoria internacional del cineasta desde su eclosión con Bienvenido Mister Marshall, sin olvidar su participación en coproducciones internacionales y su relación con técnicos y actores extranjeros, como sucedió en algunas de sus mejores películas como Calabuch (1956), Los jueves milagro (1957), La muerte y el leñador (1962), El verdugo (1963), La boutique (1967) y Tamaño natural (1974).
\end{abstract}

Palabras clave: Berlanga, Festival de Cannes, Oscars, cine español, franquismo.

\section{THE INTERNATIONAL RELEVANCE IN BERLANGA'S CINEMA}

ABSTRACT: Luis García Berlanga is perhaps the most important Spanish film director who has given. However it is not as well known internationally as he deserves. His international accolade begins in 1953 in the Cannes Film Festival, where he won two awards with his brilliant film Bienvenido Mister Marshall (1952). Between that year and 1981 the director participates repeatedly in the top film festivals in the world: Cannes, Venice, Berlin, and one of his best films, Plácido (1961), nominated for an Oscar. This article is to remind the international career of filmmaker since hatching with Bienvenido Mister Marshall, including his participation in international co-productions and their relationship to foreign technicians and actors, as in some of his best films as Calabuch (1956), Los jueves milagro (1957), La muerte y el leñador (1962), El verdugo (1963), La boutique (1967) and Tamaño natural - Life size (1974).

Keywords: Berlanga, Cannes Film Festival, Oscars, spanish cinema, franquismo. 


\section{Berlanga en España y fuera de ella}

Luis García Berlanga es, probablemente, el director de cine más destacado de la historia del cine español. A nivel estatal, además, es uno de los creadores más populares y reconocidos por el gran público, ya que muchas de sus películas, además de haber sido reconocidas por la crítica, y premiadas en festivales, también han cosechado grandes éxitos de público. En muchas ocasiones y en diferentes ámbitos se emplea el término berlanguiano para definir una situación esperpéntica comparable a cualquier secuencia de las películas del realizador valenciano. Las corruptelas y tejemanejes de las altas y bajas esferas políticas hispanas, sucedidos absurdos e insólitos, episodios tan significativos como el acaecido en la isla Perejil en 2002, o la simulación de secuestro que se inventó un concejal de un partido conservador español en 1998, son algunas de las situaciones que podrían aparecer perfectamente en un film de Berlanga. La mayoría de la población española conoce las obras más importantes de la filmografía del valenciano. Hace varios años, un diario convocaba un concurso de réplicas famosas de películas españolas. Ganó, por abrumadora mayoría, el célebre discurso de José Isbert desde el balcón del Ayuntamiento de Villar del Río de Bienvenido Mister Marshall (1952): “(...) como alcalde vuestro que soy os debo una explicación, y esta explicación que os debo os la voy a pagar $(. . .)^{\prime \prime 1}$. Ahora bien, que la repercusión de la obra berlanguiana en España sea enorme a todos los niveles, al haber sido el valenciano, además, un personaje mediático, es algo que queda fuera de toda duda al ser consideradas tres de sus películas: la citada Bienvenido Mister Marshall, Plácido (1961) y El verdugo (1963), como tres de las mejores obras cinematográficas de la historia del séptimo arte nacional, como así ha trascendido en diferentes ocasiones.

Otro caso distinto, que es lo que aquí nos atañe, es analizar la proyección y la repercusión de Berlanga y su cine en el extranjero. Repasando su filmografía, podemos apreciar que el eco internacional que tuvo el cine del director que nos ocupa, se desarrolló entre los años 1953 y 1974 aproximadamente. El punto de partida para la internacionalización del cine del valenciano fue su paso por el Festival de Cannes, en cuya edición de 1953 participó con Bienvenido Mister Marshall, obteniendo dos galardones: el premio a la mejor película de humor y el de la Fipresci al guión del filme². Paradójicamente, 1974 fue el año en que Berlanga realizó su película más internacional y una de las más inclasificables dentro de su filmografía, la inusual coproducción con Francia e Italia, rodada en París, titulada Tamaño natural (1974). Obra compleja con reparto internacional, sin embargo, fue una de las películas de Berlanga que peor respuesta del públi-

1. Diario El País. Suplemento EP3. Viernes 9 de Septiembre de 2005.

2. La Fipresci es el jurado de la prensa cinematográfica internacional en los más prestigiosos certámenes del mundo. 
co tuvo. Además, paradójicamente, a partir de este film y coincidiendo con la muerte de Franco y la transición a la democracia, la obra del levantino se hizo más española, en cuanto a la temática se refiere, y su importancia internacional como director fue perdiendo, dejando paso a otros realizadores españoles.

Si Berlanga y, en menor medida Bardem, es el cineasta español más internacional de los cincuenta y parte de los sesenta, podemos decir que Carlos Saura se erige en nuestro realizador con más repercusión internacional desde los sesenta a los ochenta ${ }^{3}$, y Pedro Almodóvar, tomando el relevo del aragonés, se convierte en el director español con más éxito fuera de nuestras fronteras a partir, sobre todo de finales de los ochenta ${ }^{4}$. No hemos de olvidar la reciente repercusión internacional de la corta carrera del joven director de origen chileno Alejandro Amenábar, quien junto con Almodóvar desde inicios del siglo XXI, es nuestro director más internacional ${ }^{5}$.

Centrémonos en el tema que nos atañe que es la repercusión internacional del cine y la figura de Berlanga. Para hablar de ello hemos de referirnos a varios aspectos susceptibles de análisis: el paso por festivales y la obtención de premios internacionales, la participación en coproducciones con otros países del mundo, básicamente europeos, la distribución de la obra berlanguiana en Europa principalmente y, por último, la repercusión crítica de la misma.

\section{Bienvenido Mister Marshall, punto de arranque de la carrera internacional de Berlanga}

El espaldarazo internacional del cine de Berlanga se produce con el éxito cosechado por Bienvenido Mister Marshall en el Festival de Cannes de 1953. Una vez pasado el trago del estreno español, acaecido el 4 de abril del mismo

3. Carlos Saura ganó el Oso de plata al mejor director del Festival de Berlín por La caza (1965), en 1966, y por Peppermint Frappé (1967), un año más tarde. En el mismo certamen se alzó con el Oso de oro a la mejor película por Deprisa, deprisa (1981). En el Festival de Cannes tampoco le fue mal al obtener sendos premios del jurado por La prima Angélica (1973), en 1974 y Cría cuervos (1975), un año después.

4. Pedro Almodóvar obtuvo el Oscar al mejor film de habla no inglesa por Todo sobre mi madre (1999), tras haber sido nominado para el mismo premio, sin conseguirlo, por Mujeres al borde de un ataque de nervios (1987). El otro premio de la academia que ostenta es el recibido por Hable con ella (2003), en la categoría de mejor guión original. Estos dos laureados filmes también obtuvieron el reconocimiento del cine francés y ganaron el premio al mejor film extranjero en la gala de los César.

5. La consecución de sendos Oscars por parte de estos dos últimos autores por las ya citadas Todo sobre mi madre y Hable con ella (Almodóvar) y Mar adentro (2004) (Amenábar), así como una buena distribución internacional de sus películas, avaladas por sus numerosos premios, han originado que el cine de Almodóvar sea conocido en todo el mundo, y que el de Amenábar, tras llevar a cabo la coproducción Los otros (2001), y lograr el éxito de la ya citada Mar adentro, siga presumiblemente el mismo camino. 
año, sábado de gloria, la película se presentó en el certamen galo, donde obtuvo un gran éxito, cosechando el premio internacional a la película de humor del jurado y una mención especial para el guión de la Fipresci, como ya hemos citado con anterioridad.

Bienvenido Mister Marshall se proyectó el 23 de abril de 1953 en el Palacio del Festival de Cannes, cosechando un gran éxito de público. A diferencia de los críticos españoles, que buscaban defectos y carencias en el filme de un director principiante, sus homólogos franceses, halagaron a la película tras constatar la acogida popular cosechada en su premiere en el festival de la Costa Azul. Son interesantes algunos de los comentarios suscitados por medios del país vecino al respecto del pase de Bienvenido, Mister Marshall, en el festival galo. Reproduzcamos algunos de ellos. En Nice-Matin, la crítica firmada por Mario Brien decía lo siguiente al respecto del filme:

(...) Éxito completo. Gran sorpresa. El cine español entra en este festival por la puerta grande. Está inscrito entre los favoritos para el "rush" final. Esta película podría cosquillear desagradablemente el amor propio de los americanos si no tomaran el partido de reír, si no aceptaran deportivamente esta sátira de sus costumbres, si no admitieran que está tratada sin malignidad definida y con infinito espíritu $(. . .)^{6}$.

Otras críticas que demuestran la fenomenal acogida del filme en el país vecino aparecieron en algunos medios de comunicación tan prestigiosos como Le Figaro, Combat y L'ecran.

En Le Figaro se decía lo siguiente: “(...) Hemos encontrado buena diversión, una fantasía que no carece de humor, bondad, poesía. Una autosátira que, sin embargo, carece de malicia (...) no podemos por lo menos que expresar gran satisfacción ante lo que es un éxito sin tacha $(. . .)^{\prime \prime}$. Respecto a este comentario, aunque es positivo, se equivoca quien lo suscribe, en lo que concierne a la malicia, porque esta abunda en el significado soterrado de la película.

En lo que respecta a la crítica de Combat, en ella se leía ésto: “(...) Una buena sorpresa. Nadie esperaba tantas buenas calidades y humor de los españoles, pues hasta ahora nunca habían sido demasiado brillantes en el festival (...)". Suponemos que se refiere al cine español anterior en el festival francés, que poco tenía que ver con las nuevas propuestas de Bardem y Berlanga.

La crítica de L'ecran fue positiva también y hacía extensivo su comentario a la capacidad de mejora del cine español: "(...) Nos ha proporcionado gran placer. Tiene pequeños gags excelentes, por ejemplo el de la profesora a la que un niño de seis años le sopla debajo de la mesa cuando, al no recordar algo, le da una patadita. Un hallazgo, y no es el único (...) La prueba de que el cine espa-

6. TENA, A. 50 aniversario de Bienvenido Mister Marshall. Ed. Tf. Madrid 2002, pp. 127-128. 
ñol puede mejorar y que ya lo está haciendo $(. . .)^{\prime \prime 7}$. Recordemos que el citado gag, así como las secuencias oníricas que preceden al desenlace, fueron las escenas más aplaudidas en el pase de la película en el festival francés ${ }^{8}$.

Tras obtener en el palmarés de Cannes los mencionados galardones, Berlanga, aprovechando el tirón del momento, viajó a París, para estrenar su filme en la capital de Francia y comenzar, de ese modo, su carrera internacional ${ }^{9}$. En julio de 1953, estrenó la película en el parisino cine Marbeuf, obteniendo más de ocho millones y medio de francos en sus siete semanas de cartel $^{10}$. Dos años más tarde, en 1955, Bienvenido Mister Marshall, Ilegó a Londres, estrenándose en el cine Curzon y recibiendo buenas críticas. En un despacho de la agencia Efe, se citaban referencias al filme del Daily Mail: "(...) Una comedia española sencillamente encantadora (...)", del Daily Herald: "(...) Alegre disparate contado con buen humor (...)", y a la revista Spectator: "(...) Agradable comedia al estilo de Don Camilo (... $)^{\prime 11}$. Por otro lado, algunos otros medios, como el Times califican al filme de forma más tibia como "(...) Una broma familiar española $(\ldots)^{\prime \prime 12}$.

Por último, el filme de Berlanga tardó otros dos años más, en llegar a los Estados Unidos de América. En mayo de 1957 se estrenó en Washington D.F., concretamente en el Dupont Theater. La acogida por parte de la crítica también fue excelente. A este respecto, es destacable comentar un artículo enviado por el corresponsal de $A B C$ en Estados Unidos que, tras vanagloriar la acogida de la película, cita el primer párrafo de la crítica del Evening Star, firmada por Harry Mac Arthur que dice lo siguiente:

“(...) Si usted lleva mucho tiempo esperando algo tangible en pago por nuestra ayuda a Europa, su espera ha terminado: los españoles han respondido con una comedia maravillosa (...) este film, tres veces premiado en Cannes, es un proyectil internacional (...) Con un poquito de francés y otro poquito de italiano la película tiene un sabor netamente español (...) Se ríe un poquito de nosotros, americanos, y otro poco de las gentes de una

7. Ibídem.

8. El premio de la crítica fue para la película de Jacques Tati, Les vacances de Mr. Hulot (Las vacaciones de Mr. Hulot, 1953), mientras que Le salarie de la peur (El salario del miedo, 1953), de Henri-Georges Clouzot se alzó con la Palma de Oro.

9. En sus idas y venidas por el país vecino, el valenciano conoció a Brigitte Bardot, con la cual iba a contar para Novio a la vista (1953), película que se rodó ese mismo verano, aunque finalmente sin la mítica actriz francesa, que cedió su puesto a Josette Arnó.

10. TENA, A. 50 aniversario de Bienvenido..., op. cit., pp. 128-129.

11. Se refiere al filme franco-italiano de Julien Duvivier, Le petit monde de Don Camilo (Don Camilo,1952), adaptación de la novela de Giovanni Guareschi, que tuvo una gran popularidad en los años cincuenta, al presentar de forma jocosa las vicisitudes de un pueblito italiano y la "rivalidad" entre un cura conservador de pueblo y un alcalde comunista.

12. TENA, A. 50 aniversario de Bienvenido..., op. cit., pp. 128-129. 
aldea española; y en ambos casos nos ven y se ven a si mismos con gracia y talento (...) Si en España quedan más películas como ésta pueden mandárnoslas ahora mismo (... $)^{\prime \prime 13}$.

Verdaderamente, críticas como ésta dan fe de la internacionalidad de la película de Berlanga, a pesar de partir de un falso enfoque local, y también hacen ver el sentido del humor de los parodiados, desde un punto de vista inteligente, que poco recuerda a la intransigencia y a las primeras reacciones contrarias a la película de algunos americanos como Edward G. Robinson ${ }^{14}$.

\section{Berlanga en los festivales de cine. Premios y participación como jurado}

Como se ha visto con anterioridad, el éxito de Bienvenido Mister Marshall en Cannes y los premios obtenidos originaron que la película se estrenase en diferentes países y que el prestigio y la popularidad de Berlanga en Europa y, en menor medida, Estados Unidos, aumentara, esperándose con impaciencia sus nuevas películas. Esta fama obtenida a nivel internacional con su segundo filme, situó al valenciano en los años cincuenta y primeros sesenta en un lugar preferente dentro del cine europeo. Del período que va desde la participación en Cannes de Bienvenido Mister Marshall, hasta el premio obtenido por El verdugo en el Festival de Moscú en 1965, podemos decir que es el momento en que Berlanga es el director español más internacional y más de moda en el cine europeo. Este período coincide con la parte inicial e incipiente de su obra (1951-1959), y con lo que hemos denominado su etapa dorada (1959-1967) $)^{15}$. A partir de este momento y hasta 1974-75 la presencia de Berlanga en certámenes foráneos y la distribución internacional de sus películas sufre un bajón que coincide con la que hemos denominado la etapa misógina de su cine. Después de la muerte de Franco, coincidiendo con la parte final de su obra, la presencia internacional del cine de Berlanga disminuye al igual que su participación en festivales extranjeros. Esta

13. Ibídem, p. 130.

14. Recordemos que este actor norteamericano, miembro del jurado de la edición de Cannes de 1953, tildó de antiamericana la película de Berlanga, para así lavar su imagen de cara a los poderes fácticos y a la opinión pública estadounidense ya que había sido sospechoso de comunismo en la tristemente célebre "caza de brujas" del "maccarthysmo".

15. Distinguimos las siguientes etapas cronológicas en el cine de Berlanga:

1. Inicial (1951-59). Desde Esa pareja feliz (1951), hasta Los jueves milagro (1957). Etapa netamente rural.

2. Etapa dorada (1959-67). Etapa urbana. Desde Se vende un tranvía (1959) a El verdugo (1963).

3. Etapa misógina (1967-1974). Se compone de tres filmes: La boutique (1967), Vivan los novios (1969) y Tamaño natural (1974).

4. Etapa "nacional" (1974-85). Compuesta por los tres filmes de la saga de los Leguineche: La escopeta nacional (1978), Patrimonio nacional (1980) y Nacional III (1982).

5. Etapa final (1985-2002). Desde La vaquilla (1985) a El sueño de la maestra (2002). 
parte de su filmografía, la de las "escopetas" y La vaquilla (1985) hasta el final de su obra, apenas tiene repercusión fuera de España ${ }^{16}$.

Centrándonos en el período 53-65, tras el ya citado éxito en Cannes de Bienvenido Mister Marshall, la siguiente película de Berlanga con destacada participación en uno de los certámenes grandes del cine europeo fue Calabuch, realizada en 1956 en coproducción por Italia. La cinta participó en la Mostra de Venecia y allí optó al León de Oro, que curiosamente ese año fue declarado desierto, pero, por el contrario, consiguió el premio de la $\mathrm{OCIC}^{17}$. En esa misma edición, el filme de Berlanga compitió con Calle Mayor (1956), de Juan Antonio Bardem, que se hizo en ese certamen con el premio otorgado por la Fipresci.

Tras los problemas de censura que soportó el levantino con Los jueves, milagro (1957) y de colaborar en el original piloto televisivo sobre los timos realizado junto a Juan Estelrich, Se vende un tranvía (1959), Berlanga vuelve al primer plano internacional en 1961 con una de sus obras maestras, Plácido. Con esta película, el valenciano logra uno de los mayores reconocimientos internacionales que puede obtener un cineasta, al ser nominado al Oscar de Hollywood a la mejor película de habla no inglesa, galardón que finalmente no ganó, pero que facilitó la distribución internacional de la película. El premio de la Academia de Hollywood en aquel año fue para Saasom $i$ en spiegel (Como en un espejo, 1961), del laureado director sueco Ingmar Bergman ${ }^{18}$. La nominación para el Oscar fue considerada por Berlanga como un sueño, y fue celebrada por el valenciano como si hubiesen obtenido el galardón. De todos modos, Plácido no fue el primer filme español que viajó a los Oscars, ya que dos años antes, La venganza (1959), de Juan Antonio Bardem tampoco pudo alzarse con la estatuilla en la ceremonia hollywoodiense ${ }^{19}$. Para Berlanga fue

16. Si exceptuamos la participación en el Festival de Cannes de Patrimonio nacional, en la edición de 1981, de donde se vino de vacío.

17. Jurado de la Organización Católica Internacional del Cine.

18. Los otros tres nominados, junto a los filmes de Berlanga y Bergman, fueron la japonesa Eien no hito (1961), de Keisuke Kinoshita, Harry og kammertjeneren (1961), del danés Bent Christensen y Ánimas Trujado (El hombre importante, 1961), del mejicano Ismael Rodríguez.

19. Tras Berlanga y Bardem, otros directores españoles que han sido nominados al galardón a la mejor película de habla no inglesa fueron: Francisco Rovira Beleta, en dos ocasiones con Los tarantos (1964) y El amor brujo (1968), Jaime de Armiñán, también dos veces con Mi querida señorita (1973) y El nido (1981), Carlos Saura con Mamá cumple 100 años (1979) y Carmen (1983), Luis Buñuel, con Tristana (1970) y Ese oscuro objeto del deseo (1977), José Luis Garci con Volver a empezar (1983), ganadora del premio, Sesión continua (1984), Asignatura aprobada (1988) y El abuelo (1998), Pedro Almodóvar con las ya citadas Mujeres al borde de un ataque de nervios (1987), Todo sobre mi madre (2000), ganadora del premio y Hable con ella (2003), nominada al mejor director y al mejor guión original, galardón este último obtenido. Fernando Trueba también obtuvo premio con Belle Epoque (1994), al contrario que Montxo Armendáriz con Secretos del corazón (1988) que se fue a casa de vacío. Por último, Alejandro Amenabar consiguió el galardón con Mar adentro (2005). (Citamos, en esta ocasión, los años en que participaron los filmes en los Oscars, no el año de producción de los mismos, el anterior en varias ocasiones). 
toda una experiencia coincidir en las fiestas previas de los premios de la academia con directores de la talla de King Vidor, Frank Capra, William Wyler o Fred Zinemann. Algunos de ellos se mostraron sorprendidos con el presupuesto de Plácido y con la destreza del valenciano para rodar algunas secuencias complejas del filme. Lo que no esperaba el levantino era ganar el premio ya que el favorito en todas las quinielas era Bergman, quien finalmente obtuvo el preciado galardón ${ }^{20}$. Pero el éxito de Plácido no acaba aquí ya que el film participó en el festival preferido de Berlanga, en Cannes, en la edición de 1962. Sería la segunda ocasión que Berlanga era seleccionado en el certamen del país vecino. En esta ocasión la suerte no sonrió como sucediera con Bienvenido Mister Marshall, pero se aseguró la distribución de la película en el estado galo, siendo la respuesta de la crítica bastante buena.

Tras dirigir un sketch de la coproducción internacional Las cuatro verdades, titulado La muerte y el leñador, basado libremente en las fábulas de Lafontaine, llegamos a 1963, año en que Berlanga lleva a cabo su otra gran película de la década, junto a Plácido. Nos referimos a El verdugo, otra coproducción con Italia que logra un gran eco internacional, avalado por la fenomenal trayectoria del valenciano en los últimos años y por la nominación al Oscar con la ya citada y precedente Plácido. Con El verdugo, Berlanga vuelve a concursar en Venecia, a donde ya había concurrido con Calabuch. En esta ocasión, este duro alegato contra la pena de muerte contado en clave satírica, consiguió el premio de la Fipresci. Habiendo gustado a la crítica europea, la película obtuvo también reconocimiento en Francia, donde fue acreedora del premio al humor negro de la Academia del Humor de ese país. Dos años más tarde, en 1965, el filme llegó a la Unión Soviética y allí, en el Festival de Moscú se hizo con el premio de la crítica soviética. La película, que arremetía contra la pena de muerte existente en la España de principios de los sesenta, con su turismo incipiente y su "apertura" al exterior, fue bien recibida por la crítica especializada y el público de la extinta Unión Soviética, que aplaudían la reprobación de Berlanga al sistema político franquista y no entendían muy bien como un realizador tan castigado por la censura, (recordemos el caso de Los jueves milagro), había podido dirigir una película tan atrevida sin haber sido advertido por el ente censor. Sin embargo, se montó un gran revuelo político en España por la participación del filme en Venecia y el estreno en salas de la película no fue tan bien como se esperaba y al valenciano le costó bastante sacar un nuevo proyecto adelante.

Desde 1967 hasta 1974, Berlanga entra en lo que podemos llamar su etapa misógina, de la mano de un contrato firmado con el productor gallego Cesáreo

20. De todo esto se habla en GÓMEZ RUFO, A. Berlanga. Contra el poder y la gloria. Ed. Temas de hoy. Madrid 1990, pp. 190-194. En esta obra hay un epígrafe dedicado al viaje de Berlanga a Estados Unidos optando al premio de la Academia. Se titula: Hollywood, en busca de un Oscar. 
Gonzalez, manteniendo su prestigio internacional, y realizando tres extrañas e inclasificables películas con importante repercusión internacional, la fallida $L a$ boutique (1967) rodada en Argentina, respecto a la cual hablaremos posteriormente, la infravalorada Vivan los novios (1969), que es también seleccionada en el Festival de Cannes de 1970, de donde se viene de vacío, y la coproducción con Francia e Italia, Tamaño natural (1974), a la que aludiremos también en el siguiente epígrafe. En este período, el valenciano también es elegido miembro del jurado del Festival de Berlín, concretamente en 1968, certamen en el que curiosamente nunca competiría con sus películas ${ }^{21}$.

A partir de este momento hasta el final de su filmografía, la obra de Berlanga se hace más nacional, más española y más propia de un consumo interno, con la trilogía de los Leguineche y con unas obras finales descontextualizadas y no tan brillantes como las películas de su etapa dorada, con excepción de La vaquilla. De este período hay que citar que en 1979 el valenciano vuelve al Festival de Cannes, pero, en este caso en calidad de jurado. Dos años más tarde, en 1981, teniendo en cuenta la bonita historia existente entre el certamen y el valenciano, Patrimonio nacional es seleccionada al certamen galo, aunque no obtuvo ningún premio, como hemos constatado con anterioridad ${ }^{22}$. De aquí en adelante, Berlanga ha sido objeto de numerosos homenajes en festivales y certámenes nacionales e internacionales obteniendo galardones honoríficos como la Orden italiana del Commendatore o siendo considerado como uno de los cineastas más prestigiosos del mundo por el festival checo de Karlovy Vary.

\section{Berlanga y las coproducciones extranjeras}

De la amplia filmografía de Berlanga, seis de sus obras fueron coproducciones con tres países. En tres ocasiones, el valenciano contó con capital italiano: Calabuch, Los jueves milagro y El verdugo. En otras dos veces acometió coproducciones con el país trasalpino y Francia: La muerte y el leñador y Tamaño natural,

21. Compartieron jurado con Berlanga en esta edición de 1968, los alemanes Peter Schamoni y Karsten Peters, el francés Georges de Beauregard, el norteamericano Gordon Hitchens, el italiano Domenico Meccoli, el sueco Carl-Eric Nordberg, el brasileño Alex Viany y el británico Alexander Walker. Este jurado otorgó el Oso de Oro a la película sueca de Jan Troell, Ole dole doff (1968), siendo Carlos Saura, por Peppermint frappé, el premiado como mejor director con el Oso de plata. Suponemos que Berlanga tuvo algo que ver en ello.

22. En la edición de Cannes de 1979, acompañaron como miembros del jurado a Berlanga las siguientes personas vinculadas al séptimo arte: el director francés Jules Dassin, el realizador húngaro Zsolt Kezdi-Kovacs, la actriz británica Susannah York, el escritor soviético Robert Rojdestvensky, los periodistas franceses Maurice Bessy y Rodolphe M. Arlaud, el guionista italiano Sergio Amidei y el productor francés Paul Claudon, siendo presidenta del jurado la escritora gala Françoise Sagan. Este jurado otorgó la Palma de Oro del año ex aequo a Die bletchrommel (El tambor de hojalata, 1979), de Volker Schlondörff y Apocalypse Now (1979), de Francis Ford Coppola. 
y, por último, en una colaboró con un país más lejano pero muy unido culturalmente a España, Argentina, para Ilevar a cabo La boutique. Entre 1956 y 1974, por tanto, momento álgido de Berlanga en el panorama cinematográfico internacional, tan solo dos filmes de los que realiza en este período son producciones netamente españolas, nos referimos a Plácido y Vivan los novios, lo cual deja bien a las claras la confianza de los productores extranjeros, principalmente de países tan cercanos a España como Francia o Italia para entrar en proyectos del valenciano, que había intervenido con éxito en los festivales cinematográficos más importantes de estos países, Cannes y Venecia, como veíamos con anterioridad.

La situación autárquica de España, tras la Guerra Civil va dando paso paulatinamente a la apertura al exterior y a la firma de convenios de coproducción entre España y otros países, entre los que destacan Italia y Francia, estados que entraron en la coproducción de algunas películas de Berlanga. Esta dinámica de la colaboración internacional tenía un estímulo para los países extranjeros y era que los salarios de los profesionales españoles eran más bajos que los de sus países de origen. Otra de las causas que estimulaban las coproducciones era la apertura de nuevos mercados para estas naciones. El contraste entre la anquilosada industria del cine español con cinematografías más competitivas y avanzadas como la francesa o la italiana, provocó un desajuste y, en muchos casos, por culpa de la censura, un viraje hacia productos comerciales de calado menor $^{23}$. Entre las excepciones de estas coproducciones se hallan diversas películas de Berlanga, filmes que vamos a repasar brevemente.

Desde el punto de vista cronológico la primera coproducción en la que interviene Berlanga es Calabuch en 1956, producida por la compañía hispana Águila Films y la italiana Film Costellazione ${ }^{24}$. La participación italiana originó la presencia en el reparto de dos actores trasalpinos tan destacados como Valentina Cortese y Franco Fabrizi, así como la intervención del prestigioso guionista Ennio Flaiano, y en menor medida de los músicos Guido Guerrini y Angelo Francesco Lavagnino ${ }^{25}$. El elenco internacional se completaba con el anciano Edmund Gwenn, que también daba salida a la película a mercados anglosajo-

23. HEREDERO, C. Las huellas del tiempo. Cine español 1951-1961. Ed. Filmoteca Española y Filmoteca Valenciana. Madrid 1994, pp. 103-105.

24. Calabuch es la única coproducción con España en la que entró esta compañía que estuvo en activo entre los años 1952 y 1959.

25. Sin embargo Flaiano no estuvo a la altura de las circunstancias según Berlanga, quien admiraba al italiano, gran guionista en películas de Fellini como Otto e mezzo (Ocho y medio,1963) o La Strada (1959). Este prestigioso escritor repetiría con el valenciano, de todos modos, en 1963, ya que participó, asimismo, en el guión de El verdugo. Véase en HERNÁNDEZ LES, J. e HIDALGO, M. El último austro-húngaro. Conversaciones con Berlanga. Ed. Anagrama. Barcelona 1981, p. 60. Guerrini sólo intervino como compositor en la película que nos atañe, mientras Lavagnino participó en 201 producciones de todos los pelajes entre 1948 y 1988, siendo uno de los compositores italianos más prolíficos en aquellos cuarenta años. 
nes $^{26}$. La película se vio en Italia, tras su paso por Venecia, y en Gran Bretaña y Estados Unidos, entre otros países destacados. En Italia, curiosamente, adoptó el título original Calabuig, cambiado por Calabuch por motivos de posible confusión con la pronunciación de este nombre en castellano. El título anglosajón era aún más explícito: The rocket from Calabuch. El filme llegó subtitulado a Gran Bretaña de la mano de Curzon Film distributors y a Estados Unidos, gracias a Trans Lux Inc. en 1958.

Sólo un año más tarde, en 1957, Berlanga realiza también en coproducción con Italia Los jueves milagro. En esta ocasión la producción española corría a cargo de Ariel Films, mientras que la compañía italiana que cooperaba en la obra era la empresa Domiziana Internazionale Cinematografica, que se iniciaba en la producción con la película de Berlanga, y que repetiría la experiencia de coproducir con España en años posteriores ${ }^{27}$. En este caso, el título elegido por los italianos difería del español y de ese modo la película se conoció en Italia como Arrivederci Dimas, mientras que para el mercado anglosajón el título elegido fue el explícito Miracles of Thursday, más afín al nombre original en castellano. En esta ocasión, el reparto tenía dos reclamos internacionales destacados, uno, de nuevo, para el mercado anglosajón con el popular intérprete estadounidense Richard Basehart, y otro enfocado a Italia con la presencia del entrañable, y no menos mítico, Paolo Stoppa, y en menor medida con la participación del actor secundario Luigi Tosi y la del músico Franco Ferrara ${ }^{28}$.

En 1962, Berlanga acometió una de las experiencias más curiosas en su filmografía, una especie de paréntesis entre sus dos películas más redondas, Plácido y El verdugo. Nos referimos al sketch integrado dentro del film de episodios Las cuatro verdades, codirigido por los prestigiosos directores René Clair, Alessandro Blasetti y Hervé Bromberger, titulado La muerte y el leñador. Los cuatro sketches, como ya citábamos con anterioridad, estaban basados libremente en conocidas fábulas de Lafontaine. En este caso, la coproducción

26. Edmund Gwenn contaba con 92 años en 1956 y sólo un año antes había rodado con Hitchcock The trouble with Harry (Pero... quien mató a Harry, 1955), siendo un actor conocido y reputado en Estados Unidos.

27. Otras tres películas españolas que coprodujo esta empresa fueron Diez fusiles esperan (1959), de José Luis Sáenz de Heredia, Se necesita chico (1963), de Antonio Mercero y Noche de verano (1963), de Jorge Grau.

28. Actores prolíficos, todos ellos eran estrellas en sus países y conocidos ampliamente a nivel internacional. Richard Basehart trabajaba un año antes en Moby Dick (1956), de John Huston, donde acompañaba al mítico Gregory Peck, mientras que Paolo Stoppa era recordado por películas tan emblemáticas como Stazione Termini (Estación Termini, 1953) o Miracolo a Milano (Milagro en Milán, 1951), ambas de Vittorio de Sica. Luigi Tosi era un secundario frecuente en películas italianas de todos los tipos en los cincuenta y sesenta. Por su parte, Franco Ferrara tan sólo compuso la banda sonora de seis películas en el mismo período. No obstante, trabajó en unos noventa filmes como conductor musical. 
fue diferente a la de películas anteriores ya que la participación italiana de la productora Ajace Produzioni Cinematografiche se centraba en el episodio de Blasetti, mientras que las empresas francesas Franco London Films y Madeleine Films, hacían lo propio con los sketches firmados por Clair y Bromberger. La parte española del proyecto, la dirigida por Berlanga, fue producida por Hispamer Films. Coordinada la producción por Gilbert de Goldschmitt, la viabilidad internacional de la película era evidente por la reputación de los directores. Berlanga codirigía una película con uno de los cineastas más admirados por él en los inicios de su carrera, René Clair. Como reclamo internacional, el reparto del episodio del valenciano fue protagonizado por el alemán Hardy Kruger, quien ya tenía un nombre en el cine internacional al intervenir en filmes como Hatari (1962) de Howard Hawks ${ }^{29}$. Titulada para el mercado francés como Les quatre verités, y para el italiano como Le quatro veritá, el filme, en su versión subtitulada para los Estados Unidos adoptó el cursi nombre de Three fables of love, quedando fuera del jocoso tono de estas tres fábulas amorosas, la parte filmada por Berlanga, la más corrosiva de la película, sin duda alguna ${ }^{30}$.

La tercera coproducción, sólo con Italia, que dirigió Berlanga fue la mítica El verdugo, en 1963. En esta ocasión, la compañía italiana que trabajó en la película con las empresas españolas Interlagar y Naga Films, fue la productora trasalpina Zebra Films. En lo que concierne a la participación italiana en la obra, desde el punto de vista artístico es destacable la presencia del conocido actor italiano Nino Manfredi en el papel protagonista, aunque a Berlanga más le hubiese gustado que este papel lo hubiese encarnado un actor español ${ }^{31}$. En menor medida, Guido Alberti aparece en el elenco interpretativo en un rol secundario, el de director de la cárce ${ }^{32}$. Desde el punto de vista técnico Berlanga tuvo la suerte de contar por segunda vez con el guionista Ennio Flaiano, de cuyo trabajo en esta ocasión tuvo menos queja el valenciano que en el caso de Calabuch, aunque su presencia fue bastante más testimonial, ya que la fuerza del guión residía en el trabajo de Rafael Azcona y el propio Berlanga. Tam-

29. Aunque este actor no era del agrado del valenciano, quien hubiese preferido que su papel lo hubiese llevado a cabo cualquier otro intérprete español, preferiblemente alguno de los habituales que trabajaban con él como José Luis López Vázquez.

30. Desde el sistema franquista se criticó la sórdida imagen que se daba de Madrid, dentro de un contexto más jocoso, que era el que imperaba en el resto de los episodios.

31. Nino Manfredi (1921-2004), es uno de los actores más destacados de la comedia italiana de los sesenta y setenta junto a otros intérpretes reputados como Marcello Mastroianni, Vittorio Gassman, Ugo Tognazzi y Alberto Sordi. Auténtico hombre orquesta, destacó principalmente en la interpretación encarnando tipos medios italianos entrañables, pero también escribió una quincena de guiones, dirigió tres películas, entre ellas la exitosa Las tentaciones de Benedetto (Per grazia ricevuta, 1971).

32. Guido Alberti fue un buen actor secundario italiano que intervino en diversos filmes trasalpinos como el ya citado Otto e mezzo, de Federico Fellini. 
bién se contó con el destacado director de fotografía Tonino Delli Colli, uno de los principales profesionales italianos en este campo, qué ha trabajado, entre otros con Federico Fellini, Sergio Leone o Roman Polanski ${ }^{33}$. La película contó con el título italiano La ballata del boia (La balada del verdugo) y, gracias al éxito del film en su andadura festivalera se hizo con una interesante distribución internacional. Para el mundo anglosajón el filme se estrenó con el extraño título Not on your life.

La penúltima película de Berlanga que se llevó a cabo por medio de coproducción internacional fue La boutique, en 1967. Contratado por el productor gallego Cesáreo González, Berlanga entró en nómina de éste y llevó a cabo la ya citada película y la interesante y minusvalorada Vivan los novios, tres años más tarde, en 1970, acabada y estrenada tras la muerte del citado productor ${ }^{34}$. En este caso, la coproducción se llevó a cabo con Argentina y la película se rodó allí con equipo técnico y artístico de este país, resultando el filme uno de los más inclasificables y desconocidos de la filmografía berlanguiana. La empresa argentina que coprodujo la película fue Argentina Sono Films ${ }^{35}$. La obra fue comercializada en este país con el título Las pirañas, más apropiado que el que se utilizó en España y que figuraba dentro de los títulos originales del guión junto con La víctima. El filme es uno de los peores de Berlanga y la coproducción con Argentina no hizo sino descontextualizar al cineasta valenciano, a diferencia de sus colaboraciones con otros países europeos.

La última película de Berlanga realizada en coproducción con otras naciones fue Tamaño natural, obra producida en 1974. Tras completar su contrato con Cesáreo González, con la ya citada Vivan los novios, que participó en el Festival de Cannes, como ya comentábamos con anterioridad, Berlanga llevó a cabo su película más internacional y, probablemente más inclasificable. Rodada en Francia y con un fenomenal reparto internacional encabezado por Michel Piccoli ${ }^{36}$, Rada Rassimov y algunos de los intérpretes españoles habituales del valenciano, en esta ocasión cinco fueron las compañías internacionales que entraron en el proyecto: la francesa Film 66, que había intervenido en la producción de La grande bouffe (1973), de Marco Ferreri, un año antes, las tam-

33. Experimentado y curtido en mil batallas, el director de fotografía romano trabajó en, nada menos, 140 películas compartiendo rodaje con algunos de los mejores directores de la historia del cine como los ya citados, además de Louis Malle, Jean-Jacques Annaud, Roberto Benigni, Marco Ferreri o Pier Paolo Pasolini.

34. La apuesta de fichar a Berlanga se produce en un intento de González de ganarse un prestigio teniendo en nómina a algunos de los directores más internacionales de nuestro cine y a otros exponentes del Ilamado Nuevo Cine Español. Ver CASTRO DE PAZ, J. L. Suevia Films. Cesáreo González. Treinta años de cine español. Ed. Xunta de Galicia 2005, p. 140.

35. Argentina Sono Films (S.A.C.I.) ha producido más de 200 películas desde 1933 a la actualidad.

36. Quien repetiría con Berlanga encabezando el reparto de París-Tombuctú (1999). 
bién galas, Les Productions Fox Europa y Uranus Production France, la española Jet Films, con la que Berlanga ha trabajado en diferentes momentos de su carrera $^{37}$, y la italiana Verona Produzione. En el apartado técnico destaca la presencia del prestigioso músico Maurice Jarre ${ }^{38}$. En lo que concierne a los títulos con los que se comercializó la cinta, podemos citar hasta cuatro, dependiendo del país de origen o destino del filme. En Francia el título escogido fue Grandeur nature, mientras que en Italia a la película se la conoció por Grandezza naturale, mientras que la denominación elegida para su distribución por el mundo anglosajón fue Life Size. La película llevó a cabo una desigual carrera internacional y no fue estrenada en España hasta 1978, tras la muerte de Franco y en el ámbito del comienzo del aperturismo a la democracia.

\section{A modo de conclusión}

Para finalizar, es preciso decir que Berlanga ha sido uno de los realizadores españoles más internacionales de la historia de nuestro séptimo arte, aunque seguramente no llegó a ser internacionalmente tan popular o conocido como lo es ahora Pedro Almodóvar, desde su irrupción en el cine europeo a partir de los años ochenta. Sin embargo, Berlanga ha sido referente y parte importante del cine europeo merced a la repercusión mediática de sus filmes y a la participación de algunas de sus obras en los más prestigiosos certámenes cinematográficos europeos, sobre todo entre 1953 y 1974. El estilo, los temas o los guiones de algunas de sus películas han sido imitados por cineastas de distintas procedencias, que, en algunos momentos, han tomado obras del valenciano como punto de partida. Este es un tema, sin embargo, que dejamos para una ocasión más propicia.

37. Otras películas del valenciano con intervención de Jet Films en la producción son, las ya citadas Plácido, Patrimonio nacional, Nacional III y La vaquilla.

38. El francés Maurice Jarre es uno de los compositores más prestigiosos del cine mundial, que ha trabajado en más de 170 películas a lo largo y ancho de su carrera, algunas de ellas como Ghost (1990), de Jerry Zucker, o Dead poets society (El club de los poetas muertos, 1989), de Peter Weir, por citar dos ejemplos, auténticos éxitos del cine comercial americano. 